\title{
Windows into the ivory tower
}

\author{
Engagement between scientists and the public can take many forms, but it needs time, \\ funds and opportunities for local contact. There should be ongoing effort to create such \\ opportunities.
}

This month, at the annual meeting of the International Society for Stem Cell Research (ISSCR), scientists, policymakers, journalists and patient advocates will gather in Stockholm to discuss stem cell research. Somewhat atypically for a scientific conference, there will also be an open forum where members of the public can ask questions and air their concerns. Such occasions are important opportunities to promote understanding and dialogue.

At earlier iterations of the ISSCR forum, attended by editors of this journal, there was a palpable and bitter feeling from some members of the public of having been let down, of research not proceeding as fast as had been hoped. It illustrated well how talk of potential cures for disease is immediately personal for the afflicted, and how important it therefore is to temper excitement in research with realistic descriptions of which benefits are likely to emerge and when.

The challenge of sending an informed and realistic message is one that the ISSCR has undertaken vigorously in the past years. Although the need for nuanced public engagement is arguably most pressing in medically relevant fields such as regenerative or genomic medicine and in politically (and indeed existentially) important ones like the science of climate change, this holds for other research areas too. Even basic research is carried out with the license and support, including public funding, of society. Disseminating the knowledge gained through this research is a legitimate part of the contract. More practically, maintaining funding requires public support.

Especially among younger scientists, the fact that there is value to public communication is increasingly appreciated. Outreach officers-which exist at several types of institutions, including universities, funders and societies-say that scientists these days are rarely unwilling to help communicate subjects related to their work, something that was not always true in decades past. And scientists do also stand to benefit directly from the process: describing one's work to nonspecialists can put it in a different and often illuminating perspective.

Is the public interested? There is good reason to think that, for a substantial number of people, the answer is yes. The recent exhibition "Unlocking Life's Code" at the Smithsonian Museum of Natural History in Washington, DC, for example, organized in partnership with the National Human Genome Research Institute, reportedly had 3 million visitors. TED talks on seem- ingly obscure scientific topics are visited online many hundreds of thousands of times. According to a PewAAAS survey published earlier this year, close to $80 \%$ of American people view the effect of science on society positively, though a similar fraction think that science education in the nation is subpar. Anecdotal experience matches this finding: most people, not only in America, hold the scientific endeavor in high esteem, though many feel insufficiently informed about it.

Scientific information is disseminated via many routes outside of formal education. These include direct efforts by scientists-lectures, panels, blogs and visits to schools, for instance-as well as more indirect channels: journalism in different media, pedagogical projects such as the Smithsonian exhibition or science fairs, or artistic projects like those funded by the Sloan Foundation's public understanding of science program. Organizations such as the Science Media Centre (operating in several countries) or Sense about Science (in the UK and, more recently, the US) collate expert comment on scientific subjects receiving attention in the press, among other activities.

Scientists are a necessary part of these undertakings, serving to frame a topic for the media, as expert commentators or as advisors for more involved projects. And for genuine dialogue, there is still no real substitute for interactive engagement between the public and scientists themselves, globalization and the internet notwithstanding. None of this is easy to do well. It takes commitment, experience and, invariably, talent or training or both to express complex concepts and research findings simply but accurately, and in a way that is relevant to nonspecialists. In-depth public engagement that goes beyond simple communication, as in the recent public consultation on mitochondrial replacement therapy in the UK, takes yet another level of planning and time.

Although communication to the public is not for everyone, it is important that opportunities are created for scientists to get locally involved and that those who do so are recognized and rewarded. The more scientists who participate, even if only at a small scale, the better distributed will be both the benefits of public engagement and the necessary time commitment. There is much to gain from the ongoing cultivation of a public with a sophisticated understanding of the wonder and the promise, but also the limits, of scientific research. 